\title{
DETACHMENT OF ACROSOMAL CAPS OF BULL SPERMATOZOA BY COCONUT FATTY ACID MONOETHANOLAMIDE ETHOXYLATE
}

\author{
S. GOMBE, C. NORMAN* AND D. E. MBOGO $\dagger$ \\ Department of Veterinary Physiology, \\ P.O. Box 30197, Nairobi, Kenya
}

(Received 6th November 1974)

The detergents at present in use for the separation of mammalian sperm acrosomes have unwanted side effects on the spermatozoa or on the acrosomes themselves. The present study was undertaken in an attempt to obtain a more satisfactory agent. Fresh unfermented coconut milk (CME), obtained from mature coconuts, was boiled and filtered into sterile Erlenmeyer flasks. After cooling, dihydrostreptomycin sulphate $(1 \mathrm{mg} / \mathrm{ml})$ was added. Half of the CME was mixed with an equal volume of $0.2 \mathrm{M}$-phosphate buffer, $\mathrm{pH} 7.4$ (neutral $\mathrm{pH}$ GME) and the other half was mixed with an equal volume of $0.2 \mathrm{M}$-phosphate buffer, $\mathrm{pH} 5.9$ (low $\mathrm{pH}$ GME). The buffered solutions were stored in a refrigerator at 2 to $4^{\circ} \mathrm{C}$ and used as sperm diluents within the week.

A commercial mixed liquid detergent solution (LD), comprising sodium tetrapropylene benzene sulphonate (NaTBS), sodium lauryl ether sulphate (NaLES) and coconut fatty acid monoethanolamide ethoxylate (Empilan) in the ratio of $4: 1: 1$ was purchased as a $10 \%$ solution from Thika Wax Works, Nairobi. The pure components were kindly supplied by the management of Thika Wax Works as $10 \%$ solutions. Hyamine and Triton X-100 were purchased from Sigma Chemicals, U.S.A.

Good quality semen was obtained from several breeds of European (Bos taurus) and indigenous (Bos indicus) cattle from the Central Artificial Insemination Service of the Kenya Veterinary Department.

A fresh ejaculate was centrifuged at $1000 \mathrm{~g}$ for $15 \mathrm{~min}$ at $20^{\circ} \mathrm{C}$. The pellet was resuspended in low $\mathrm{pH}$ CME and recentrifuged as above. This was repeated. The final pellet was resuspended in the low $\mathrm{pH}$ CME to a volume equivalent to that of the original ejaculate and the suspension was divided into several $1-\mathrm{ml}$ aliquots.

In the first experiment, the effectiveness of LD and hyamine on the ability to release acrosomal lysozymes was compared. Three samples containing (1) no detergent, (2) $0.2 \%$ hyamine and $0.1 \%$ Triton X-100 and (3) $0.2 \% \mathrm{LD}$ and $0.1 \%$ Triton $\mathrm{X}-100$, were incubated at $37^{\circ} \mathrm{C}$ for $90 \mathrm{~min}$. The samples were centrifuged at $500 \mathrm{~g}$ for $10 \mathrm{~min}$ at $20^{\circ} \mathrm{G}$. The protein contents of the supernates was determined by the method of Lowry, Rosebrough, Farr \& Randall (1951).

* Deceased.
† Present address: Central Artificial Insemination Service, Kabete, P.O. Kabete, Kenya. 
In the second experiment, acrosomal detachment following separate exposure to the three components of LD, namely NaTBS, NaLES and Empilan was investigated. Aliquots $(1 \mathrm{ml})$ of the sperm suspension containing $1 \%$ of the above detergents were incubated for $90 \mathrm{~min}$ at $37^{\circ} \mathrm{C}$ as before.

The third experiment was carried out to determine the minimal effective concentration of Empilan and the influence of temperature on acrosomal detachment. Aliquots $(1 \mathrm{ml})$ of sperm suspension containing $0.02,0.05,0 \cdot 1,0.5$ or $1.0 \%$ Empilan were incubated at $37^{\circ} \mathrm{C}$, room temperature and 2 to $4{ }^{\circ} \mathrm{C}$ for 2, 3, 4 or $5 \mathrm{hr}$. Thereafter, the samples were kept at 2 to $4^{\circ} \mathrm{C}$ and sperm smears were made at intervals of 24,48 and $72 \mathrm{hr}$.

In the fourth experiment, the $\mathrm{pH}$ of the incubation was changed from 5.9 to $7 \cdot 4$. Aliquots $(1 \mathrm{ml})$ of sperm suspension containing the same concentration of Empilan as above were incubated for the same time intervals.

Sperm smears were air-dried, fixed in absolute alcohol for $5 \mathrm{~min}$ and stained

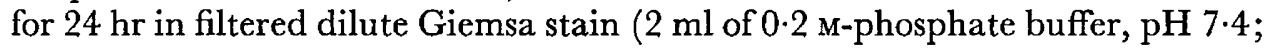
$3 \mathrm{ml}$ concentrated Giemsa solution; $25 \mathrm{ml}$ distilled water). The slides were washed in running distilled water to remove excess stain, dried and mounted in DePeX. Smears were photographed under oil-immersion at a magnification of 871 with a Leitz Wetzler orthomat.

It was found that proteins released by hyamine and by the LD were similar in all the trials. The actual quantities varied with the population of spermatozoa in the original ejaculate. With both agents, separation of the acrosomes was complete. Most of the acrosomes in the hyamine-treated samples, however, were dissolved leaving very few intact acrosomal caps. The reverse was true in LD-treated samples in which intact caps were fairly numerous. There was a tendency for LD-treated spermatozoa to flocculate on incubation.

Exposure to NaLES caused little separation of the acrosomal caps but its effect on the sperm tails was quite marked. With short incubations, the tails tended to spiral but the spermatozoa remained separate; with longer incubation, the spermatozoa clumped together by their tails. The tails themselves showed evidence of swelling, breakage and dissolution of the plasma membranes (P1. 1, Figs 1 and 2).

The extent of clumping was most marked with NaTBS even within minutes of addition. After incubation for $2 \mathrm{hr}$ in a $1 \%$ concentration, all the acrosomal membranes had been dissolved away from the spermatozoa and the spermatozoa appeared in tight clumps (PI. 1, Fig. 3).

The most effective separation of the acrosomal caps with minimal fragmentation or dissolution of the membranes was obtained with Empilan (Pl. 1, Fig. 4); the spermatozoa were intact and unfragmented, and the tails were straight, resembling those of the controls (Pl. 1, Fig. 1). Most spermatozoa in the other treatments had shed their acrosomes.

At $\mathrm{pH} 5 \cdot 9,1 \%$ Empilan was as effective at room temperature as it was at $37^{\circ} \mathrm{C}$ in causing acrosomal detachment. At 2 to $4^{\circ} \mathrm{C}$, however, this concentration of Empilan caused the same degree of separation only after 3 days. When the $\mathrm{pH}$ was raised to $7 \cdot 4$, almost $100 \%$ acrosomal detachment was effected by incubation in $1 \%$ Empilan at 2 to $4{ }^{\circ} \mathrm{C}$ for $2 \mathrm{hr}$. Even $0.1 \%$ Empilan at pH $7 \cdot 4$ was adequate to cause almost $100 \%$ detachment of acrosomal caps after incuba- 


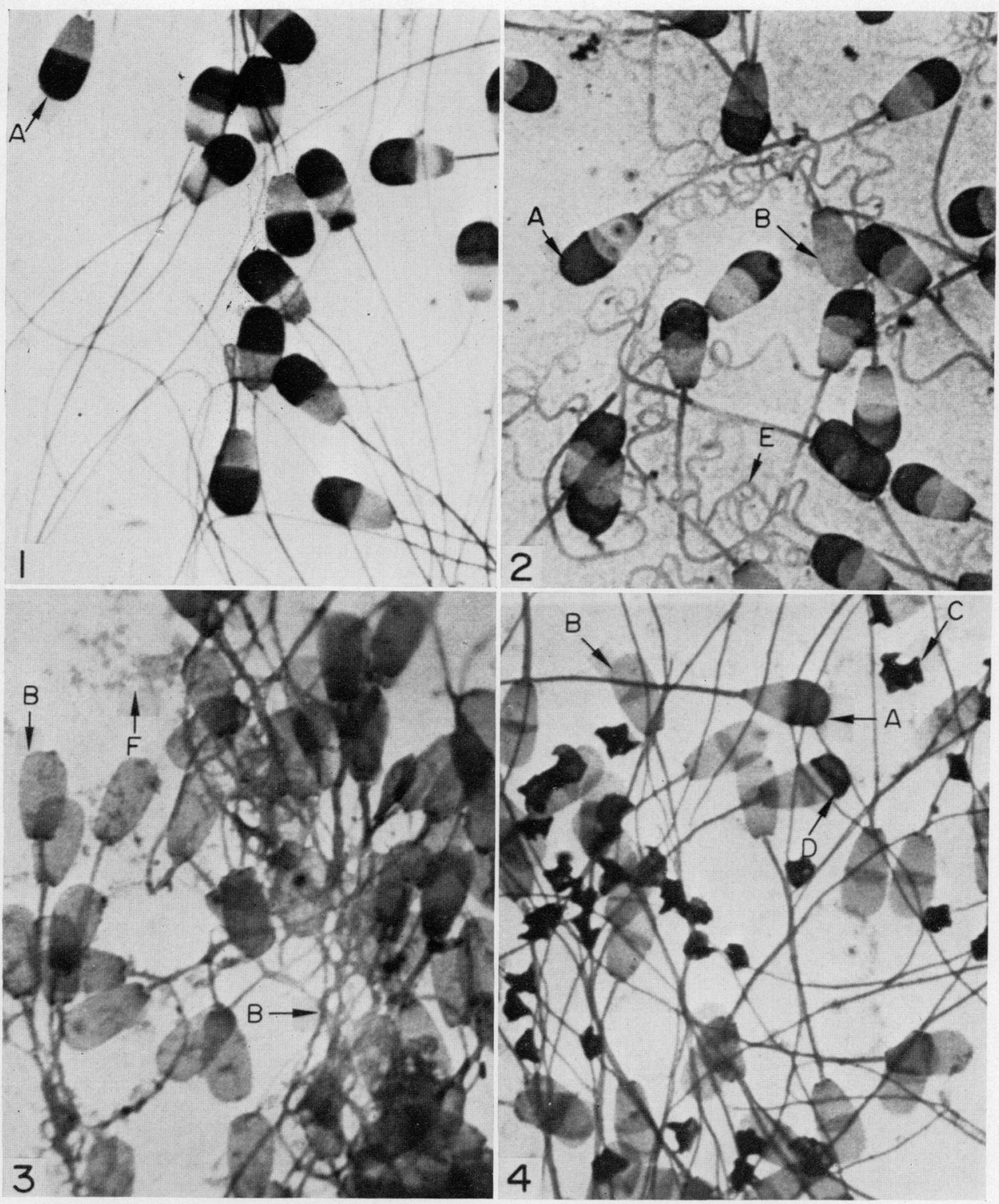

Appearance of bull spermatozoa after exposure to various detergents during incubation at $37 \mathrm{C}$ for $2 \mathrm{hr}$ followed by incubation at 2 to 4 for a further $70 \mathrm{hr}$. $\mathrm{A}=$ Spermatozoon with intact acrosome; $\mathrm{B}=$ spermatozoon with completely detached acrosome; $\mathrm{C}=$ detached acrosomal membrane; $\mathrm{D}=$ spermatozoon with partly detached acrosome; $\mathrm{E}=$ spiralled and swollen tails $; \mathrm{F}=$ acrosomal debris.

FIG. 1. Control spermatozoa.

FIG. 2. Spermatozoa after incubation in $1 \%$ sodium lauryl ether sulphate.

FIG. 3. Spermatozoa after incubation in $1 \%$ sodium tetrapropylenebenzene sulphate.

FIG. 4. Spermatozoa after incubation in $1 \%$ coconut fatty acid monoethanolamide ethoxylate (Empilan).

(Facing p. 536) 
tion for $2 \mathrm{hr}$ at room temperature or $37^{\circ} \mathrm{C}$. This was regarded as the optimal operating condition.

Hathaway \& Hartree (1963) found that cetyltrimethylammonium bromide (CTAB) caused dissolution of acrosomal membranes and clumping of the denuded spermatozoa. It is evident that CTAB, NaTBS and hyamine do not attack the acrosomal membranes specifically, but NaLES appeared to attack the sperm tails and the action of Empilan was mainly on the acrosomes. This demonstrates not only a difference in the acrosomal membranes from the rest of the sperm plasma membrane but also that specificity of action could be achieved by different detergents.

The staining characteristics of intact control acrosomes and those of acrosomes separated with Empilan were similar. The denuded spermatozoa that had been treated with Empilan also had the same pale-staining sub-acrosomal regions and red tails as the control spermatozoa. This suggests that Empilan did not effect acrosomal detachment through disruption or dissolution of the membrane but by loosening the cementing material between the acrosomal caps and the sperm heads.

The small quantities of Empilan needed to effect total separation and the relative unimportance of operating temperature favour its substitution in place of the detergents at present in use. It remains to be shown, however, that Empilan does not inactivate the released acrosomal enzymes. The demonstration by Topps \& Elliot (1965) that the more powerful detergent, CTAB, did not inactivate acrosomal enzymes may indicate that Empilan would be safe to use in this respect.

This work was assisted in part by fellowship awards from the Population Council and National Science Foundation to the first and second author respectively.

\section{REFERENGES}

Hathaway, R. R. \& HARTrez, E. F. (1963) Observations on the mammalian acrosome: experimental removal of acrosomes from ram and bull spermatozoa. F. Reprod. Fert. 5, 225-232.

Lowry, O. H., Rosebrough, N. J., Farr, A. L. \& Randall, R. J. (1951) Protein measurement with the Folin phenol reagent. F. biol. Chem. 193, 265-275.

Topps, J. H. \& EluIot, R. C. (1965) Enzymatic action of lipoglycoprotein preparation from sperm acrosomes on rabbit ova. Nature, Lond. 205, 498-499. 